pneumonitis with the laryngeal mask airway. Can J Anaesth 1992; 39: 69-70.

3 Editorial: Laryngeal mask airway. The Lancet 1991; 338: 1046-7.

4 The Intavent Laryngeal Mask Instruction Manual, 2nd Ed. Available from: Vitaid Ltd, PO Box 123, Stn St, Toronto, Ontario M5M 4L6.

5 Griffin RM, Hatcher IS. Aspiration pneumonia and the laryngeal mask airway. Anaesthesia 1990; 45, 12: 1039-40.

6 Brain AIJ. The laryngeal mask and the oesophagus. Anaesthesia 1991; 46: 701-2.

\section{Early detection of airway obstruction with a capno- graphic probe attached to an oxygen mask}

To the Editor:

Capnometry and pulse oximetry are effective in preventing anaesthetic mishaps ${ }^{1,2}$ and ensuring adequate ventilation ${ }^{3}$ in sedated patients. We report a case in which airway obstruction was detected by capnography, but not by pulse oximetry.

A 71-yr-old man, scheduled to undergo inguinal hernia repair, was continuously monitored with ECG, pulse oximeter $\left(\mathrm{SpO}_{2}\right)$, and capnography. The capnographic probe (Capnomac, Datex) was inserted into and attached to an oxygen face mask near the nostrils (Figure 1). After establishment of epidural anaesthesia, midazolam $5 \mathrm{mg}$ and butorphanol $1 \mathrm{mg}$ were given $i v$. One minute later, capnographic waves were abruptly distorted and flattened (Figure 2). The patient was apnoeic for $25 \mathrm{sec}$.

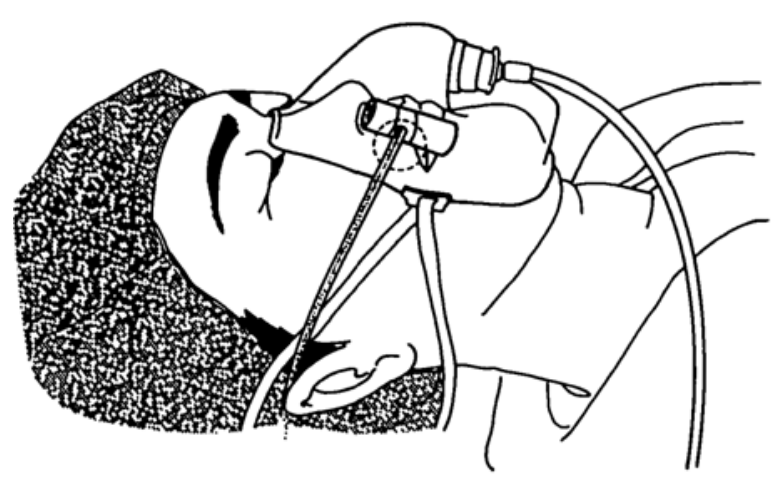

FIGURE 1 Capnographic probe attached inside the oxygen face mask near the nostrils of the patient.

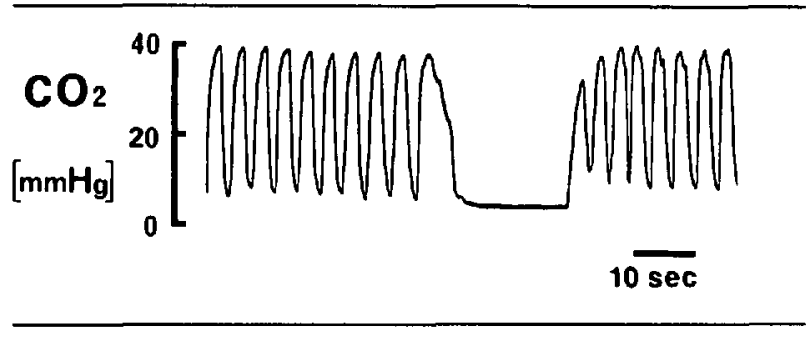

FIGURE 2 Capnographic tracings. After sedatives were given, $\mathrm{CO}_{2}$ value decreased markedly and reached baseline level. The patient was apnoeic for $25 \mathrm{sec}$.

During this period, $\mathrm{SpO}_{2}$ (99\%) and haemodynamic variables remained unchanged. Immediately after moving the lower jaw to open the airway, the capnographic waves reappeared, indicating a patent upper airway of the patient.

In our monitoring system no additional devices are required. Although a leak around the face mask may cause dilution of the expiratory $\mathrm{CO}_{2}$, we believe that our technique can monitor trends of $\mathrm{CO}_{2}$ output, and thus aid in the early detection of airway obstruction.

Shinichi Inomata MD

Toshiaki Nishikawa MD

Department of Anaesthesiology

Institute of Clinical Medicine

University of Tsukuba

Tsukuba City, Ibaraki 305

Japan

\section{REFERENCES}

1 Tinker JH, Dull DL, Caplan RA, Ward RJ, Cheney FW. Role of monitoring derives in prevention of anesthetic mishaps: a closed claims analysis. Anesthesiology 1989; 71: 541-6.

2 Bailey PL, Pace NL, Ashburn MA, Moll JWB, East KA, Stanley $T H$. Frequent hypoxemia and apnea after sedation with midazolam and fentanyl. Anesthesiology 1990; 73: 826-30.

3 Goldman JM. A simple, easy, and inexpensive method for monitoring $\mathrm{ETCO}_{2}$ through nasal cannulae. Anesthesiology $1987 ; 67$ : 606 .

\section{Technology transfer and monitoring practices}

To the Editor:

The penultimate stage in the life of a successful monitoring device is its routine use by clinicians. This is 
encouraged by experts and by establishing standards of practice for a community. However, the recommendations are not universally accepted and some anaesthetists have deplored resistance to change in monitoring practices. Coercive remedies have been suggested.' However, moni- tors can only be employed effectively if their use is voluntary and well understood.

The term "technology transfer" refers to the transition of a device from development and evaluation to routine clinical use. Publications about technology offer alternative methods to coercion and which are in addition to practice standards for anaesthesia. These methods are in keeping with the "active and latent failure model" 2 recently applied to anaesthesia accident analysis ${ }^{3}$ and are derived from consideration of the anaesthetists for whom the new technology fails to reduce stress by facilitating optimum patient care. ${ }^{4}$ This situation occurs in developing countries as well as in more advanced nations.

Stresses that may be incurred involve

(i) Health limitations, e.g., defects in colour vision or the ability to detect change of pitch in auditory signals.

(ii) Complex work station, because the new device had not been integrated.

(iii) Absence of facilities to enable the anaesthetist to act on information.

(iv) Educational deficit of anaesthetist.

(v) Inadequate information regarding the value of the device.

In conclusion, assuming that lessons can be learned from other occupations, the invaluable pronouncements of high profile anaesthetists needs support from physicians and administrators in the institution.

All those factors which tend to induce stress will need to be addressed before new technology is accepted into the anaesthetist's work station.

\author{
Dr. J.W.R. McIntyre \\ Professor Emeritus \\ Department of Anaesthesia \\ Faculty of Medicine \\ University of Alberta \\ Edmonton, Alberta
}

\section{REFERENCES}

1 Cooper JB, Gaba DM. A strategy for preventing anesthesia accidents. Int Anesthesiology Clin 1989; 27: 148-52.

2 Reason $J$. The contribution of latent human failures to the breakdown of complex systems. Phil Trans R Soc Lond 1990; 327: 475-84.

3 Eagle $C J$, Davies $J M$. Accident analysis of large scale technological disasters applied to an anaesthetic complication. Can J Anaesth 1992; 39; 118-22.

4 MCIntyre JWR. Anaesthesia monitoring; the human factors component of technology transfer. Int J of Clin Monitoring \& Computing. In press.

\section{Transient swelling of the parotid glands following laryngeal mask airway}

\author{
To the Editor:
}

The laryngeal mask airway has been widely used for an adjunct to airway management during anaesthesia. ${ }^{1}$ We recently experienced a case of swollen parotid glands after general anaesthesia with a laryngeal mask airway as described below.

The patient was a 42-yr-old woman weighing $54 \mathrm{~kg}$, and was admitted to undergo transvaginal hysterectomy for myoma. She had been diagnosed with bronchial asthma for three years and had been administered aminophyllin (200 $\mathrm{mg} \cdot \mathrm{day}^{-1}$ ) and tranilast $\left(300 \mathrm{mg} \cdot \mathrm{day}^{-1}\right)$. Preoperative examination was normal except for the decrease in FEV1\% (56\%). She was premedicated with famotidine $20 \mathrm{mg}$ iv $60 \mathrm{~min}$ before, and with atropine $0.4 \mathrm{mg}$ and hydroxyzine $25 \mathrm{mg}$ im $30 \mathrm{~min}$ before the operation. General anaesthesia was induced with midazolam (10 $\mathrm{mg}$ ) and vecuronium (6 $\mathrm{mg}$ ), followed by the insertion of a laryngeal mask airway (size 4). Anaesthesia was maintained with $0.5-1.5 \%$ isoflurane, in $67 \%$ nitrous oxide and $33 \%$ oxygen. After a two-hour operation, she recovered uneventfully from anaesthesia. Then, the laryngeal mask airway was removed and she was transferred to the recovery room. The next morning she complained of slight tenderness in the parotid area bilaterally, where soft and elastic masses were felt and diagnosed as acute bilateral parotid gland swelling by an otorhinolaryngologist. The swelling disappeared within $48 \mathrm{hr}$ and within $60 \mathrm{hr}$ of the end of anaesthesia.

Salivary gland swelling after general anaesthesia has been reported as a rare complication of general anaesthe$\mathrm{sia}^{2,3}$ occurring in three out of 1500 patients undergoing general endotracheal anaesthesia. ${ }^{2}$ Similar swelling has been reported after peroral endoscopic examination. ${ }^{4}$ The cause is considered to be associated with transient obstruction of the salivary gland duct by mechanical compression with an endoscope or endotracheal tube and acceleration of salivary secretion during endoscopic examination or endotracheal anaesthesia. ${ }^{2.4}$ Swelling of the parotid glands observed in our case might have a similar aetiology. However, because the volume occupied 